\title{
PERSONALITY, ACCULTURATION, AND PSYCHOSOCIAL ADJUSTMENT OF CHINESE INTERNATIONAL STUDENTS IN GERMANY ${ }^{1,2}$
}

\author{
JINGYU ZHANG \\ Institute of Psychology \\ Chinese Academy of Sciences \\ Graduate University of the Chinese Academy of Sciences
}

HEINZ MANDL

Department of Psychology

Ludwig-Maximilian-University of Munich
ERPING WANG

Institute of Psychology

Chinese Academy of Sciences

Summary. - The effect of personality traits and acculturation variables on crosscultural adjustment were investigated in 139 Chinese students in Germany (52\% girls; $M$ age $=25.3$ yr., $S D=2.9$ ). Participants were surveyed by house visits to their dormitories. Several scales were administered: (a) Big Five Inventory; (b) Vancouver Index of Acculturation; (c) sociocultural adjustment, general and academic; and (d) psychological adjustment, i.e., depression, self-esteem, and life satisfaction. Results showed that Neuroticism and Openness were two shared predictors of sociocultural adjustment. Agreeableness and mainstream acculturation were only related to general adjustment, while Conscientiousness was only related to academic adjustment. All facets of psychological adjustment were related to Neuroticism and Consciousness, while positive components (self-esteem and life satisfaction) were also related to Extraversion and Openness. No influence of heritage acculturation was found. The findings are discussed in light of measurement issues and the shared and unique individual predictors of the different facets of adjustment.

International students often experience acculturative stress related to their adjustment to a new culture (Barker, Child, Gallois, Jones, \& Callan, 1991; Berry, 1994). Despite the global trend of a growing interest in understanding the nature of adjustment and causes of effective adjustment (Ward, Leong, \& Low, 2004; Wang \& Mallinckrodt, 2006), little research has been done on international students in Germany. This is quite incompatible with the country's prominence in the international education market (Isserstedt \& Link, 2008). Chinese students have now become the largest group of foreign students in Germany with their number still growing rapidly (13.8\% of all foreign students with an annual growth rate of about $17 \%$; Isserstedt \& Link, 2008). However, since this group of students commonly experiences more acculturative stress than their European counter-

\footnotetext{
${ }^{1}$ Address correspondence to Erping Wang, Institute of Psychology, Chinese Academy of Sciences, 4A Datun Rd., Chaoyang District, Beijing, 100101, P.R. China or e-mail (wangep@ psych.ac.cn).

${ }^{2}$ This study was supported by the NSFC key project (70731004) and the Knowledge Innovation Project of the Chinese Academy of Sciences (KSCX2-YW-R-130).
} 
parts in Western countries (Yeh \& Inose, 2003), it seems urgent and necessary to conduct direct research to study adjustment in this particular group. The present research addresses the issue of the cross-cultural adjustment of Chinese international students attending German universities by examining the different dimensions of adjustment and the influences of personality and acculturation factors on these dimensions.

\section{Cross-cultural Adjustment}

Psychological adjustment and sociocultural adjustment are two interrelated but theoretically and practically different constructs in cross-cultural transitions (Ward, Bochner, \& Furnham, 2001). Psychological adjustment, commonly measured by scales of depression or mood disturbance, focuses on the emotional reactions during cross-cultural transitions (Ward \& Kennedy, 1993, 1994). Sociocultural adjustment, generally measured by the day-to-day difficulties people encounter in a foreign culture, focuses on an individual's knowledge and ability to function effectively in the new cultural context (Ward \& Kennedy, 1999). However, a recent trend in positive psychology suggests putting more emphasis on positive self-image and well-being which could be also seen as part of psychological adjustment (Naughton \& Wiklund, 1993; Larson, 2000). Meanwhile, researchers of sociocultural adjustment have suggested that it is necessary to separately investigate the specific work-related (or academic) adjustment and general adjustment (understanding the general social environment), because the two are functionally different and may have different predictors (Shaffer, Harrison, Gregersen, Black, \& Ferzandi, 2006). For example, a hardworking Chinese student with a traditional worldview may have good academic performance but may not find it easy to understand German politics, values, and social issues. In response to these emerging concerns, the present research measured a more comprehensive set of psychological (depression, self-esteem, and life satisfaction) and sociocultural adjustments (difficulties in general and academic domains) and investigated their shared and unique antecedents.

\section{Personalities and Cross-cultural Adjustment}

Personality traits are important in cross-cultural adjustment because they influence the way people interact with a particular environment and may serve as risks or buffers for adjustment problems (John, Naumann, \& Soto, 2008). Regarded as the predominant theory of personality today, the Big Five theory of personality describes five personality traits (Neuroticism, Extraversion, Openness to Experience, Agreeableness, and Conscientiousness) which provide a useful framework for understanding the relationship between personality and adjustment in cross-cultural transitions (Costa \& McCrae, 1992; Ward, et al., 2004; Swagler \& Jome, 2005). 
Sociocultural adjustment could be facilitated by social learning and an adaptive coping style (Furukawand \& Shibayama, 1993; Ward \& Kennedy, 1999). There are two shared predictors of both general and academic sociocultural adjustment supported by empirical evidence (Furukawand \& Shibayama, 1993; Ryder, Alden, \& Paulhus, 2000; Ward, et al., 2004). These are Openness to Experience, which is related to actively seeking new experiences and intellectual curiosity, and Neuroticism, which is related to maladaptive coping responses (John, et al., 2008). One difference between general and academic adjustment is that the latter is more task-oriented. In this way, Conscientiousness, related to impulse control and personal striving in goal- and task-directed behavior (John, et al., 2008), is particularly important for academic adjustment. Empirical research has shown that this personality trait could predict better academic performance and less delinquency (Chen \& Piedmont, 1999; Farsides \& WoodWeld, 2003; Noftle \& Robins, 2007).

Another way to facilitate social adjustment is through establishing social networks (Ward, et al., 2001). Agreeableness, defined as a prosocial and communal orientation toward others, and Extraversion, defined as energetic approach toward the social and material world (John, et al., 2008), are theoretically important in this process. Evidence has shown that people higher in Agreeableness are more likely to build a firm relationship with host country nationals which can enhance general sociocultural adjustment (Ones \& Viswesvaran, 1997). However, it has been suggested that the agreeable Asian students are more likely to avoid conflict and are more compliant to authority such as professors (Ones \& Viswesvaran, 1997; Ward, et al., 2004). This may prove ineffective in cultures like Germany where assertiveness and confrontation are greatly emphasized in education and working environments (House, Hanges, Javidan, Dorfman, \& Gupta, 2004). Extraversion, also from the perspective of cultural fit (Ward, et al., 2004), is not appreciated equally across cultures (Hofstede, 2001), which can sometimes produce negative outcomes such as social rejection or depression (Shaffer, et al., 2006; Ward, et al., 2004).

For sociocultural adjustment, it was hypothesized that both Neuroticism and Openness would be the shared predictors of both general and academic adjustment (Hypothesis 1), while Conscientiousness would be only related to academic adjustment (Hypothesis 2) and Agreeableness would be only related to general adjustment (Hypothesis 3).

Psychological adjustment is directly linked to neuroticism, vulnerability to stress, and maladaptive coping responses (John, et al., 2008). People high in neuroticism suffer greater psychological problems, particularly depression (Costa \& McCrae, 1992). A stressful international experience would make this link more salient because the established social support 
system no long exists (e.g., Bakker, van Oudenhoven, \& van der Zee, 2004; Ward, et al., 2004). Psychological adjustment could also be effectively facilitated by problem-focused coping through self-regulation (Ward, et al., 2001), which is directly linked to conscientiousness. Evidence suggests that higher conscientiousness predicts less depression, less anxiety, fewer problems related to attention deficit, and higher life satisfaction (Costa \& McCrae, 1992; Krueger \& Tackett, 2006).

The positive components of psychological adjustment differ from the negative component (depression) in that they have a positive emotionality content directly linked to Openness and Extraversion. Individuals high in Openness generally enjoy better self-image and life satisfaction (McCrae, 1996), and they are more likely to enjoy the new experience when entering a new culture (Swagler \& Jome, 2005). Meanwhile, individuals high in Extraversion are more likely to have a better self-evaluation and higher life satisfaction across cultures due to positive emotionality (DeNeve \& Cooper, 1998; Diener, Oishi, \& Lucas, 2003).

Concerning psychological adjustment, Neuroticism and Conscientiousness would be the shared predictors of all three facets (Hypothesis 4), while Openness and Extraversion would be related to the positive components of psychological adjustment (Hypothesis 5).

\section{Acculturation and Cross-cultural Adjustment}

Acculturation is another important factor in influencing an individual's adjustment, which may even add more predictive power to personality variables for explaining different adjustment outcomes (Swagler \& Jome, 2005). Defined as a process of individual level changes in cultural features, acculturation happens when people from different cultural backgrounds come into contact (Gibson, 2001). Berry (1997) proposed that people who are acculturating can develop host cultural practices (mainstream acculturation) while maintaining their own home cultural practices (heritage acculturation) at the same time. Based on the bidimensional model which separately measures people's attitudinal and behavioral preferences in both mainstream and heritage culture (Ryder, et al., 2000), researchers found that greater heritage acculturation was related to better psychological adjustment (Sam \& Berry, 2006), while greater acculturation with the mainstream culture was associated with greater sociocultural adjustment (Ward \& Kennedy, 1994; Ward \& Rana-Deuba, 1999). It stands to reason that individuals who have a higher preference for the host culture would have more knowledge about how to function in that culture and enjoy better general sociocultural adjustment. However, this may not necessarily result in adjustment in academic settings. Meanwhile, those who show a strong preference for their ethnic culture may feel more security in 
adhering to their culture which would result in less identity conflict and psychological stress (Leong \& Ward, 2000).

As a result, it was hypothesized that greater mainstream acculturation (to German culture) would only be related to greater general sociocultural adjustment (Hypothesis 5), whereas greater heritage acculturation (to Chinese culture) would be associated with all facets of psychological adjustment (Hypothesis 6). Finally, Hypothesis 7 was that the acculturation variables would add more predictive power to personality variables in predicting all adjustment outcomes.

\section{Method}

\section{Participants}

Chinese students $(N=139)$ in Munich, Germany, took part in the first study. The sample comprised 66 men and 73 women, with ages ranging from 20 to 35 years $(M=25.3, S D=2.9)$. In terms of marital status, 64 $(45.3 \%)$ were single, $17(12.9 \%)$ were married, and $58(41.7 \%)$ were in a serious relationship. For those who were not single, 8 of 17 and 25 of 58 were living with their partners in the same city, respectively. The average duration of residence in Germany was 33.2 mo. ( $S D=29.0, M d n=24$ mo.).

Materials

Big Five Inventory of Personality (Benet-Martínez \& John, 1998; John \& Srivastava, 1999). - In order to maintain a balance between efficiency and reliability, the present research adopted the established Chinese version of the 44-item Big Five Inventory of Personality (Benet-Martínez \& John, 1998). This scale is shorter and easier to understand than the 240item NEO-FFI, without undermining the core attributes of the Big Five (John, et al., 2008). It has been shown to be reliable for cross-language and cross-cultural research (Schmitt, Allik, McCrae, \& Benet-Martínez, 2007). Cronbach's alphas for each dimension were .81 (Neuroticism), .79 (Extraversion), .82 (Openness), .72 (Agreeableness), and .79 (Conscientiousness).

Vancouver Index of Acculturation (Ryder, et al., 2000). - This 20-item scale was used to measure participants' preferences and identification with both mainstream (German) and heritage (Chinese) culture by 10 parallel items such as, "I always celebrate Chinese (German) holidays" and "I love to make Chinese (German) friends," in a 9-point Likert-type scale with anchors of 1: Strongly disagree and 9: Strongly agree. This scale has sound validity and reliability (Ryder, et al., 2000; Huynh, Howell, \& BenetMartínez, 2009). The Chinese version of this scale was administered verbally by the author. For the current sample, $\alpha=.85$ for heritage culture and $\alpha=.81$ for mainstream culture.

Sociocultural Adaptation Scale (Ward \& Kennedy, 1999). - This 29-item scale was devised to measure general adjustment by listing a variety of sit- 
uations or activities people may experience in a foreign culture (e.g., making friends, finding their way around, etc.). Participants were required to rate the difficulty of each situation using a 5-point scale with anchors of 1 : No difficulty and 5: Extreme difficulty, with higher scores reflecting more adjustment problems. In the present study, this scale was translated into Chinese and adapted to fit the current sample. First, a back-translation procedure was adopted: a bilingual assistant translated this scale into Chinese, and then it was back-translated into English by another assistant. Inconsistencies were resolved through discussion. Second, in a pilot study, 16 participants were asked to rate these items and point out the relevance of these items to their life in Germany and ease of understanding. Three items (religion, family relationships, and dealing with people staring) were discarded because most participants felt these were either irrelevant to their life or hard to understand. Finally, the rest of the 26 items were used in the present study and they were of good internal consistency $(\alpha=.92)$.

Academic Adjustment Scale (Ward \& Kennedy, 1999).-This 4-item scale, with similar rating methods and translation procedures as the Sociocultural Adaptation Scale, was added to measure the more specific adjustment in academic settings. Participants were required to rate the difficulties in academic activities such as, "Dealing with the teachers and staff at your university." In the current sample, $\alpha=.75$.

Zung Self-rating Depression Scale (Zung, 1965; Wang, Wang, \& Ma, 1999). - The established Chinese version of this 20-item instrument was used to assess affective, physiological, and psychological components of depression. Participants were asked to rate how often (from 1: Never to 4: Very often) they had feelings such as, "I have trouble sleeping at night" and "I feel hopeful about the future (R)." In the current sample, $\alpha=.83$.

Rosenberg Self-esteem Scale (Rosenberg, 1965; Wang, et al., 1999). - The established Chinese version of this 10-item scale was used to measure positive self evaluation. Participants were asked to rate how often (from 1: Never to 4: Very often) they had feelings such as, "On the whole, I am satisfied with myself." In the current sample, $\alpha=.93$.

Satisfaction with Life Scale (Diener, Emmons, Larsen, \& Griffin, 1985).The established Chinese version of this 5-item scale was used as a positive aspect of psychological adjustment. Participants were asked to rate to what extent they agree with statements like, "In most ways my life is close to my ideal" (from 1: Strongly disagree to 7: Strongly agree). In the current sample, $\alpha=.93$.

Demographic Variables

In addition to sex, resident time in Germany, marital status, companionship, and age, a self-rated confidence in German language was also measured with a single item "How confident are you in using the German 
language" with options from 1: Have no confidence to 5: Have great confidence.

\section{Procedure}

The first author made visits to the student dormitories to distribute questionnaires. By checking the name list at the entrance of each dormitory (updated monthly by Munich Studentenwerk, who was in charge of these dormitories), room numbers with Chinese names were recorded first and visited later. Among 372 rooms visited, 159 students at home were invited to participate in this research, all of whom agreed. Then the questionnaires were left with the participants for them to complete anonymously and the researcher went back one hour later to collect the questionnaires. The return rate was $94.0 \%$ (142 questionnaires). Three cases were excluded due to too many missing values, thus the final sample was 139.

\section{RESUlts}

First, the possible influence of participants' sex, age, residence time, language confidence, marital status, and companionship were correlated with all five adjustment outcomes (Barker, et al., 1991; Ward \& Rana-Deuba, 1999; Yeh \& Inose, 2003). Correlation analysis suggested that greater time in Germany and higher confidence in the German language were significantly correlated with fewer general adjustment difficulties $(r=-.18$, $p<.05$, and $r=-.23, p<.01$, respectively), but not with other variables. Oneway ANOVA analyses showed that women $(M=4.56, S D=1.43)$ reported higher life satisfaction than men $\left(M=4.04, S D=1.53 ; F_{1,137}=4.40, p<.05\right.$; $\left.\eta^{2}=.031\right)$. Marital status also influenced participants' reported life satisfaction $\left(F_{2136}=4.63, p<.05 ; \eta^{2}=.064\right)$. Post hoc analysis showed that married people $(M=5.24, S D=1.46)$ were more satisfied than people who were single $\left(M=4.03, S D=1.46 ; \mathrm{F}=9.19, p<.01 ; \eta^{2}=.105\right)$ or in a relationship $\left(M=4.34, S D=1.46 ; F=4.79, p<.05 ; \eta^{2}=.061\right)$, while no differences were found among the latter two groups $(F=1.55, p=.22)$. As a result, this variable was used as a dummy variable $(0=$ unmarried and $1=$ married $)$. Age and partners in the same city were not found to have any influence on the five dependent variables. Language confidence, time in Germany, sex, and marital status were considered as control variables in further analysis. The zero-order correlations among all variables are presented in Table 1.

In order to test the hypotheses, five hierarchical regression analyses were separately performed by taking general adjustment, academic adjustment, depression, self-esteem, and life satisfaction as dependent variables. In the first step of each analysis, language confidence, residence time, sex, and marital status were entered as control variables. In the second step, the five personality trait scores were entered. The two acculturation variables were entered in Step 3. The final coefficients and changes of $R^{2}$ are reported in Table 2 . 
TABLE 1

Means, Standard Deviations, and Zero-order Correlations Among All Variables

\begin{tabular}{|c|c|c|c|c|c|c|c|c|c|c|c|c|c|c|c|}
\hline Variable & $M$ & $S D$ & 1 & 2 & 3 & 4 & 5 & 6 & 7 & 8 & 9 & 10 & 11 & 12 & 13 \\
\hline \multicolumn{16}{|l|}{ Controls } \\
\hline 1. Language & 3.05 & .88 & & & & & & & & & & & & & \\
\hline 2. Time & 33.23 & 28.97 & $.47 \dagger$ & & & & & & & & & & & & \\
\hline 3. Sex & .53 & .50 & .10 & -.09 & & & & & & & & & & & \\
\hline 4. Marital status & .12 & .32 & .01 & .11 & .04 & & & & & & & & & & \\
\hline \multicolumn{16}{|l|}{ Personality traits } \\
\hline 5. Extraversion & 3.12 & .69 & -.01 & .11 & .11 & .04 & & & & & & & & & \\
\hline 6. Agreeableness & 3.92 & .52 & -.09 & -.10 & -.04 & -.06 & .11 & & & & & & & & \\
\hline 7. Conscientiousness & 3.39 & .66 & .00 & -.10 & $-.17^{*}$ & .03 & -.04 & .29 & & & & & & & \\
\hline 8. Neuroticism & 2.84 & .71 & -.06 & -.02 & .13 & .02 & $-.26 \dagger$ & $-.43 \dagger$ & $-.17^{*}$ & & & & & & \\
\hline 9. Openness & 3.50 & .64 & .02 & .05 & .00 & .00 & $.48+$ & $.18^{*}$ & .09 & $-.27 \dagger$ & & & & & \\
\hline \multicolumn{16}{|l|}{ Acculturation } \\
\hline 10. Heritage & 7.06 & 1.05 & -.10 & .09 & .00 & .05 & $.18^{*}$ & $.23 \dagger$ & .10 & -.05 & .06 & & & & \\
\hline 11. Mainstream & 4.93 & 1.18 & .09 & -.15 & $.19^{*}$ & -.08 & $.25+$ & -.01 & .06 & $-.18^{*}$ & $.30 \dagger$ & -.04 & & & \\
\hline \multicolumn{16}{|l|}{ Sociocultural adjustment } \\
\hline 12. General & 1.99 & .52 & $-.23 \dagger$ & $-.18^{*}$ & .04 & .05 & $-.30 \dagger$ & $-.30 \dagger$ & -.14 & $.48 \dagger$ & $-.35 \dagger$ & .00 & $-.30 \dagger$ & & \\
\hline 13. Academic & 1.81 & .63 & -.03 & .04 & .07 & .16 & $-.23 \dagger$ & $-.31 \dagger$ & $-.29 \dagger$ & $.44 \dagger$ & $-.33 \dagger$ & -.10 & $-.21^{*}$ & $.67 \dagger$ & \\
\hline \multicolumn{16}{|l|}{ Psychological adjustment } \\
\hline 14. Depression & 36.40 & 7.86 & -.02 & .11 & .05 & -.04 & $-.30 \dagger$ & $-.37 \dagger$ & $-.29 \dagger$ & $.57 \dagger$ & $-.35 \dagger$ & -.07 & $-.30 \dagger$ & $.52 \dagger$ & $.66+$ \\
\hline 15. Self-esteem & 3.16 & .61 & .14 & -.01 & .01 & .04 & $.22^{*}$ & $.28 \dagger$ & $.34 \dagger$ & $-.35 \dagger$ & $.28 \dagger$ & .04 & .08 & $-.23 \dagger$ & $-.32 \dagger$ \\
\hline 16. Life satisfaction & 4.28 & 1.54 & .07 & .02 & $.19^{*}$ & $.23^{*}$ & $.34 \dagger$ & $.28 \dagger$ & $.25+$ & $-.37 \dagger$ & $.26+$ & .12 & $.22^{*}$ & $-.31 \dagger$ & $-.40 \dagger$ \\
\hline
\end{tabular}


TABLE 2

Hierarchical Regression Analyses of Psychosocial Adjustment

\begin{tabular}{|c|c|c|c|c|c|c|c|c|c|c|}
\hline \multirow[t]{3}{*}{ Variable } & \multicolumn{4}{|c|}{ Sociocultural Adjustment } & \multicolumn{6}{|c|}{ Psychological Adjustment } \\
\hline & \multicolumn{2}{|c|}{ General Adjustment } & \multicolumn{2}{|c|}{ Academic Adjustment } & \multicolumn{2}{|c|}{ Depression } & \multicolumn{2}{|c|}{ Self-esteem } & \multicolumn{2}{|c|}{ Life Satisfaction } \\
\hline & $\beta$ & $\Delta R^{2}$ & $\beta$ & $\Delta R^{2}$ & $\beta$ & $\Delta R^{2}$ & $\beta$ & $\Delta R^{2}$ & $\beta$ & $\Delta R^{2}$ \\
\hline Controls & & .07 & & .06 & & .03 & & .04 & & $.08^{*}$ \\
\hline 1. Language & $-.15^{*}$ & & -.09 & & -.07 & & $.21^{*}$ & & .04 & \\
\hline 2. Time & -.08 & & .13 & & .14 & & -.14 & & .01 & \\
\hline 3. Sex & .08 & & .08 & & .05 & & .01 & & .15 & \\
\hline 4. Marital status & -.14 & & $-.22^{*}$ & & .09 & & .05 & & $.21^{*}$ & \\
\hline Personality traits & & $.31 \neq$ & & $.28 \neq$ & & $.40 \neq$ & & $.23 \neq$ & & $.25 \ddagger$ \\
\hline 5. Extraversion & -.09 & & -.06 & & -.12 & & .15 & & $.22^{*}$ & \\
\hline 6. Agreeableness & $-.18^{*}$ & & -.09 & & -.12 & & .03 & & .07 & \\
\hline 7. Conscientiousness & -.04 & & $-.16^{*}$ & & $-.15^{*}$ & & $.25 \dagger$ & & $.17^{*}$ & \\
\hline 8. Neuroticism & $.30 \neq$ & & $.28 \neq$ & & $.40 \neq$ & & $-.22^{*}$ & & $-.24 \dagger$ & \\
\hline 9. Openness & -.15 & & $-.17^{*}$ & & -.12 & & $.18^{*}$ & & .04 & \\
\hline Acculturation & & $.04^{*}$ & & .01 & & .02 & & .01 & & .01 \\
\hline 10. Heritage & .07 & & -.04 & & -.01 & & -.02 & & .04 & \\
\hline \multirow[t]{3}{*}{ 11. Mainstream } & $-.20^{*}$ & & -.09 & & .14 & & -.11 & & .08 & \\
\hline & Adjus & $=.36$ & Adjust & $2=.29$ & Adjus & ${ }^{2}=.41$ & Adjus & ${ }^{2}=.22$ & Adjus & $2=.27$ \\
\hline & $F_{11,127}=$ & & $F_{11,127}=$ & & $F_{11,127}=$ & & $F_{11,127}=$ & & $F_{11,127}=$ & \\
\hline
\end{tabular}

Note. - The table containing Beta coefficients from previous steps of the regressions is on file in Document APD2010-012. Remit $\$ 10.00$ for a photocopy to the Archive for Psychological Data, P.O. Box 7922, Missoula, MT 59807-7922, for recipients inside the USA. Contact APD for shipping rates outside the USA. ${ }^{*} p<.05 . \dagger p<.01 . \neq p<.001$. 
Concerning sociocultural adjustment, the full model predicting general sociocultural adjustment was significant. More difficulties in general domains were predicted by higher Neuroticism, lower Agreeableness, and lower Mainstream Acculturation, respectively. Openness, however, was just below the significance criterion. Meanwhile, the full model predicting academic adjustment was significant. More difficulties in academic settings were predicted by higher Neuroticism, low Conscientiousness, and low Openness. It was also predicted by being unmarried. In summary, Hypothesis 1 regarding Neuroticism and Openness as shared predictors was partly confirmed. Hypotheses 2, 3, and 5 regarding the unique influence of Conscientiousness on academic adjustment, and of Agreeableness and Mainstream Acculturation on general adjustment, were fully confirmed.

Concerning psychological adjustment, the full model predicting depression was significant. Depression was predicted by higher Neuroticism and lower Conscientiousness, but not by Heritage Acculturation. The full model predicting Self-esteem was also significant. Self-esteem was predicted by lower Neuroticism, higher Conscientiousness, and higher Openness. Extraversion, however, was just below the significance criterion. It was also predicted by more confidence in German language, but not by Heritage Acculturation. The full model predicting life satisfaction was significant. Life satisfaction was predicted by less Neuroticism, higher Extraversion, and higher Conscientious. It was also predicted by being married, but not by Openness or Heritage Acculturation. In summary, Hypothesis 4 regarding Neuroticism and Conscientiousness as the shared predictors of all three facets of psychological adjustment was confirmed, while Hypothesis 5 concerning the unique influence of Openness and Extraversion on life satisfaction and self-esteem was partly confirmed. No influence of Heritage Acculturation, however, was observed (Hypothesis 6 was not confirmed).

The results also showed that the inclusion of acculturation variables only explained an additional $4 \%$ variance in predicting general sociocultural adjustment $\left(F_{2,127}=4.03, p<.05\right)$ but not in predicting other adjustment outcomes, thus only a small part of Hypothesis 7 was supported.

\section{Discussion}

The results showed that personality had a significant influence on adjustment outcomes while acculturation variables had a relatively small effect. Most importantly, this study found that different facets within sociocultural and psychological adjustment resulted from both shared and different individual variables.

Neuroticism and Openness were two shared predictors of sociocultural adjustment. This was in line with the first hypothesis that social cultural adjustment could be understood from the perspective of cultural 
learning and coping. Agreeableness and Mainstream Acculturation were only related to general adjustment, while Conscientiousness was only related to academic adjustment. This also suggests that Conscientiousness was more important for facilitating task-oriented learning while general sociocultural adjustment requires more cultural preference (Acculturation) and being social (Agreeableness). On the other hand, the nonsignificant relationship between Conscientiousness and general sociocultural adjustment indirectly suggests that understanding general society may not be considered as important or personally sought after by many Chinese students. Their primary goal may be only related to academics since they may have little to do with German society in the future.

Neuroticism and Conscientiousness were two shared predictors of all facets of psychological adjustment, in line with the hypothesis that psychological adjustment could be understood from the perspective of stress and coping. Furthermore, self-evaluation and life satisfaction were also significantly predicted by Extraversion and Openness. This pattern supported the hypothesis that the positive and negative components of psychological adjustment might have different individual bases because of their different content (positive emotional experiences). This aspect should be further examined. The present study also found that heritage acculturation had no influence on any psychological adjustment outcomes. This was inconsistent with previous findings (Ryder, et al., 2000; Swagler \& Jome, 2005; Wang \& Mallinckrodt, 2006). One explanation might be that all participants reported high heritage acculturation $(M=7.05$ on a 9-point scale, $S D=1.05$ ) in the current sample; thus, range restriction in individual differences may have prevented detection of this effect. However, this should not be treated as a mere ceiling effect or sampling error. It could be seen as evidence that the Chinese international students did not suffer from cultural identity conflicts compared to other international students or second-generation immigrants (Leong \& Ward, 2000). China's growing status in world economics and politics has given birth to a new upsurge of national pride and nationalism in overseas Chinese communities (Liu, 2005; Liu \& Hong, 2010). Therefore, the high heritage acculturation reported by Chinese students, who might be influenced by this trend as well, is worthy of further investigation.

Several limitations of this study must be noted. First, the correlational nature of this study prevents any causal relationships from being established. Second, all measures in self-report form may be influenced by common method variance which could inflate the relationships among variables. Third, most participants were from two top universities in a German metropolis, thus the ability to generalize this sample to Chinese students 
in other areas and schools is limited. Fourth, there was no control on completion of the survey since the questionnaires were finished alone by the participants in their dormitory, thus, careless or socially desirable answers might be possible. Finally, the measurement of acculturation established in an Asian student sample in North America may not be suited to Chinese students in European countries. Future research should use specifically constructed tools to understand the nature of this construct better.

The present study has several important theoretical and practical implications. First, the shared and unique predictors regarding the different facets of adjustment suggest that a more detailed classification of psychosocial adjustment might be necessary in future studies. Second, although heritage acculturation played a relatively unimportant role in influencing adjustment in the present study, it could be fruitful to investigate the meaning of this construct for Chinese students in European countries and/ or evaluate whether this construct was linked to the broader social, economic, and political environment. Finally, for policy makers or counseling psychologists who want to reduce the adjustment problems of Chinese international students, the personality and acculturation underpinnings of different adjustment outcomes should be considered. For example, to promote general adjustment, it is quite important to help students have good contacts and be open to the host culture to increase acculturation. For psychological adjustment, it may be important to help students establish a good social support system to buffer the negative influence of environmental stress and a neurotic personality.

\section{REFERENCES}

Bakker, W., van Oudenhoven, J. P., \& van der Zee, K. I. (2004) Attachment styles, personality and Dutch emigrants' intercultural adjustment. European Journal of Personality, 18, 387-404.

Barker, M., Child, C., Gallois, C., Jones, E., \& Callan, V. J. (1991) Difficulties of overseas students in social and academic situations. Australian Journal of Psychology, 43, 79-84.

Benet-Martínez, V., \& John, O. P. (1998) Los cinco grandes across cultures and ethnic groups: multitrait multimethod analysis of the Big Five in Spanish and English. Journal of Personality and Social Psychology, 75, 729-750.

Berry, J. W. (1994) Acculturation and psychological adaptation: an overview. In A. M. Bouvy, F. J. R. vande Vijver, P. Bosk, \& P. Schmitz (Eds.), Journeys into cross-cultural psychology. Lisse, The Netherlands: Swets \& Zeitlinger. Pp. 129-141.

Berry, J. W. (1997) Immigration, acculturation, and adaptation. Applied Psychology: an International Review, 46, 5-34.

Chen, M. C., \& Piedmont, R. (1999) Development and validation of the NEO-PI-R for a Taiwanese sample. In T. Sugiman, M. Karasawa, J. H. Liu, \& C. Ward (Eds.), Progress in Asian social psychology. Seoul: Kyoyook-Khahak-Sa. Pp. 105-119. 
Costa, P. T., \& McCRAe, R. R. (1992) Professional manual for the Revised NEO Personality Inventory (NEO-PI-R) and NEO Five-Factor Inventory (NEO-FFI). Odessa, FL: Psychological Assessment Resources.

DeNeve, K. M., \& Cooper, H. (1998) The happy personality: a meta-analysis of 137 personality traits and subjective well-being. Psychological Bulletin, 124, 197-229.

Diener, E., Emmons, R. A., Larsen, R. J., \& Griffin, S. (1985) The Satisfaction with Life Scale. Journal of Personality Assessment, 49, 71-75.

Diener, E., Oishi, S., \& Lucas, R. E. (2003) Personality, culture, and subjective wellbeing: emotional and cognitive evaluations of life. Annual Review of Psychology, $54,403-425$.

FARsides, T., \& WoodWeld, R. (2003) Individual differences and undergraduate academic success: the roles of personality, intelligence, and application. Personality and Individual Differences, 34, 1225-1243.

Furukawand, T., \& Shibayama, T. (1993) Predicting maladjustment of exchange students in different cultures: a prospective study. Social Psychiatry and Psychiatric Epidemiology, 28, 142-146.

Gibson, M. (2001) Immigrant adaptation and patterns of acculturation. Human Development, 44, 19-23.

Hofstede, G. (2001) Culture's consequences: comparing values, behaviors, institutions, and organizations across nations. Thousand Oaks, CA: Sage.

House, R. J., Hanges, P. J., Javidan, M., Dorfman, P. W., \& Gupta, V. (Eds.) (2004) Culture, leadership, and organizations: the GLOBE Study of 62 societies. Thousand Oaks, CA: Sage.

Huynh, Q. L., Howell, R. T., \& Benet-Martínez, V. (2009) Reliability of bidimensional acculturation scores: a meta-analysis. Journal of Cross-Cultural Psychology, 40, 256274.

IsSERSTEDT, W., \& LinK, J. (2008) Internationalization of higher education: foreign students in Germany-German students abroad 2008: results of the 18th Social Survey of the Deutsches Studentenwerk (DSW) conducted by HIS Hochschul-Informations-System. Bonn/Berlin, Germany: Federal Ministry of Education and Research.

John, O., Naumann, L., \& Sото, C. (2008) Paradigm shift to the integrative Big-Five trait taxonomy: history, measurement, and conceptual issues. In O. P. John, R. W. Robins, \& L. A. Pervin (Eds.), Handbook of personality: theory and research. (3rd ed.) New York: Guilford Press. Pp. 114-158.

John, O., \& SRIVAstava, S. (1999) The Big Five trait taxonomy: history, measurement, and theoretical perspective. In L. A. Pervin \& O. P. John (Eds.), Handbook of personality: theory and research. (2nd ed.) New York: Guilford. Pp. 102-138.

Krueger, R., \& TAckett, J. (2006) Personality and psychopathology. New York: Guilford Press.

Larson, R. (2000) Toward a psychology of positive youth development. American Psychologist, 55, 170-183.

LEONG, C., \& WARD, C. (2000) Identity conflict in sojourners. International Journal of Intercultural Relations, 24, 763-776.

LiU, H. (2005) New migrants and the revival of overseas Chinese nationalism. Journal of Contemporary China, 14, 291-316.

LiU, L., \& Hong, Y. (2010) Psychosocial ramifications of the 2008 Beijing Olympic Games. Asian Journal of Social Psychology, 13(2), 102-108. 
McCrae, R. R. (1996) Social consequences of experiential openness. Psychological Bulletin, 120, 323-337.

Naughton, M. J., \& Wiklund, I. (1993) A critical review of dimension-specific measures of health-related quality of life in cross-cultural research. Quality of Life Research, 2, 397-432.

Noftle, E., \& Robins, R. (2007) Personality predictors of academic outcomes: Big Five correlates of GPA and SAT scores. Journal of Personality and Social Psychology, 93, 116-130.

Ones, D. S., \& Viswesvaran, C. (1997) Personality determinants in the prediction of aspects of expatriate job success. In Z. Aycan (Ed.), New approaches to employee management. Vol. 4. Expatriate management: theory and research. Greenwich, CT: JAI. Pp. 63-92.

Rosenberg, M. (1965) Society and the adolescent self-image. Princeton, NJ: Princeton Univer. Press.

Ryder, A., Alden, L., \& Paulhus, D. (2000) Is acculturation unidimensional or bidimensional? A head-to-head comparison in the prediction of personality, self-identity, and adjustment. Journal of Personality and Social Psychology, 79, 49-65.

SAM, D., \& Berry, J. (2006) The Cambridge handbook of acculturation psychology. Cambridge: Cambridge Univer. Press.

Schmitt, D., Allik, J., McCrae, R., \& Benet-Martínez, V. (2007) The geographic distribution of Big Five personality traits: patterns and profiles of human self-description across 56 nations. Journal of Cross-Cultural Psychology, 38, 173-212.

Shaffer, M. A., Harrison, D. A., Gregersen, H., Black, J. S., \& Ferzandi, L. A. (2006) You can take it with you: individual differences and expatriate effectiveness. The Journal of Applied Psychology, 91, 109-125.

Swagler, M. A., \& Jome, L. M. (2005) The effects of personality and acculturation on the adjustment of North American sojourners in Taiwan. Journal of Counseling Psychology, 52, 527-536.

WANG, C., \& Mallinckrodt, B. (2006) Acculturation, attachment, and psychosocial adjustment of Chinese/Taiwanese international students. Journal of Counseling Psychology, 53, 422.

WANG, X., WANG, X., \& MA, H. (1999) Rating scales for mental health. Beijing: Chinese Mental Health Journal Press.

Ward, C., Bochner, S., \& Furnham, A. (2001) The psychology of culture shock. London: Routledge.

Ward, C., \& Kennedy, A. (1993) Psychological and sociocultural adjustment during cross-cultural transitions: a comparison of secondary students overseas and at home. International Journal of Psychology, 28, 129-147.

Ward, C., \& Kennedy, A. (1994) Acculturation strategies, psychological adjustment, and sociocultural competence during cross-cultural transitions. International Journal of Intercultural Relations, 18, 329-343.

WARD, C., \& Kennedy, A. (1999) The measurement of sociocultural adaptation. International Journal of Intercultural Relations, 23, 659-677.

WARD, C., LeOng, C., \& Low, M. (2004) Personality and sojourner adjustment: an exploration of the Big Five and the cultural fit proposition. Journal of Cross-Cultural Psychology, 35, 137. 
Ward, C., \& Rana-Deuba, A. (1999) Acculturation and adaptation revisited. Journal of Cross-Cultural Psychology, 30, 422-442.

YeH, C., \& INOSE, M. (2003) International students' reported English fluency, social support satisfaction, and social connectedness as predictors of acculturative stress. Counseling Psychology Quarterly, 16, 15-28.

Zung, W. W. K. (1965) A self-rating depression scale. Archives of General Psychiatry, $12,615-630$.

Accepted August 10, 2010. 